\title{
The diffusion of higher-status lexis in medieval England: the role of the clergy
}

\author{
RICHARD INGHAM \\ University of Westminster \\ (Received 12 July 2017; revised 3 April 2018)
}

\begin{abstract}
For Rothwell (1998: 156) 'words of ultimately French origin became part of the lexis of English as a result of the myriad daily contacts between Anglo-French and Middle English in the minds and under the pens of a whole literate class'. Although such contact interfaces between Francophone and Anglophone speakers clearly must have existed, not enough is known as to the means by which French-origin lexis was borrowed and diffused. I argue that a principal agency of contact-induced lexical change in Middle English was the clergy in their everyday role of spiritual guidance, whether or not they themselves composed religious texts. French loans in works of spiritual guidance are known to be common from the thirteenth-century Ancrene Wisse onwards (Trotter 2003a). According to contemporaneous sources, English clerics received a Francophone-medium school education (Orme 1973), which would have familiarised them with the French vocabulary used in religious instruction in chantry schools and beyond.

The various manuscripts of the Cursor Mundi, a work of lay religious instruction probably composed around 1300, also offer a revealing window on the process of lexical innovation and replacement instigated by the clergy. An analysis of variant lexical forms, native and French-origin, found in the first 10,000 lines of this work shows that the latter would go on to replace native items the majority of the time. The loss of many native variants, e.g. nip, mensk and pole, and their replacement, respectively, by envy, honour and suffer, can be attributed to the role played by the clergy in diffusing Frenchorigin items in the domains of discourse they dominated. Rather than merely reflecting the pre-existing lexical knowledge of monolingual English speakers, the clergy's use of such items initially introduced and then maintained French-origin lexemes in at least the receptive competence of such speakers. Their regular and widespread contact with the population at large would have enabled the take-up of lexical innovation via the spoken medium, thus motivating the use observed in homiletic and devotional written texts of extensive French-origin lexis.
\end{abstract}

Keywords: diffusion, loanwords, Middle English, French, clergy

\section{Introduction}

Conventional treatments of early French influence on English often leave the reader with something of a puzzle. Authors such as Dekeyser (1986) and Durkin (2014) have shown that the heyday of lexical borrowing from French occurred in the thirteenth and earlier fourteenth centuries. Yet according to still routinely cited sources such as Berndt (1972) and Thomason \& Kaufman (1988), this was a period when French was falling into disuse in England, so how French-language elements could have made such great inroads on English at this time remains a persistently intriguing question. Although the 'declinist' approach typified by these scholars has now been discredited by specialists 
in the French of England (e.g. Rothwell 1998; Trotter 2003a; Wogan-Browne et al. 2009), the process by which massive borrowing from French is supposed to have taken place, when this language had apparently lost its insular native speakers, deserves much more careful examination than it has so far received. A commonly held view, once advocated by Thomason \& Kaufman (1988), is that French influenced English in the later medieval period thanks to a process by which French speakers 'shifted' to English, taking much of their vocabulary with them. In the present article, more recent perspectives on the maintenance of French in later medieval bilingual speech communities are considered, focusing on stable bilingualism as a matrix for lexical borrowing, and particular attention is paid to the linguistic contact which bilingual speakers themselves enact, through the psycholinguistic activation of both languages, in some contexts at least. Opportunities for their interaction with monolingual English speakers is seen as a means by which Francophone lexis then influenced the native vernacular.

Pursuing this line of enquiry involves considering the areas in which French caused significant change to the English lexicon. A traditional perspective (e.g. Kastovsky 2006) highlights content domains where French loans reflected the higher status of individuals operating in those content domains, such as government, warfare, law, religion, fashion, cookery, etc. Yet it is clear from even a cursory glance at the range of French-origin lexis entering English in the medieval period that Francophone influence on the English lexicon extended to semantic areas which cannot be pigeon-holed in terms of content domains, but rather seem to represent the general vocabulary of the language. As an example, a list of French loans provided by Durkin (2014: 241) includes words such as chance, change, (to) close, join, large, pay, people, point, reason and (to) treat, but has few if any items that belong to the rather specialised content domains mentioned above. Such lexemes must have entered English due to the agency of French speakers, but not in the form of imposing words for domain-specific concepts. Another approach therefore seems necessary if the full range of Francophone influence is to be acknowledged.

In this article it is proposed that the chief effect of contact with bilingual FrenchEnglish speakers was to contribute a lexical repertoire of French origin to a higher register of English. The fuller development of this register had to await the adoption of learnèd Latinate and Greek-origin terms in the Early Modern period, but the largescale substitution of Francophone for native lexis in the thirteenth and fourteenth centuries set up the preconditions for this outcome by introducing a wide-ranging stock of alternatives (French- or native-origin) in the usage of at least some English speakers. The main conduit of this effect is then given consideration, in other words the identity of bilingual speakers who behaved as agents of contact-induced change, and interacted with the monolingual native population on a sufficient scale to bring about the large-scale alteration of the English lexicon that took place in the later medieval period.

Very few previous attempts to investigate the routeways by which French lexical items entered English in the medieval period are known to us. A standard textbook 
account highlights the role of the upper classes, who 'in changing from French to English ... transferred much of their governmental and administrative vocabulary, their ecclesiastical, legal and military terms, their familiar words of fashion, food and social life, the vocabulary of art, learning and medicine' (Baugh \& Cable 2002: 169). Such accounts imply some kind of trickle-down mechanism, in which French-origin lexis used by elite-class speakers of Norman origin eventually found its way down to the mass of the population via intervening social levels. Whilst locating the catalyst for the process in particular in the usage of speakers who used French and Latin in specialist domains, Durkin (2014: 229-30) generally followed this approach:

In the late fourteenth and fifteenth centuries ... Latin and (Anglo-)French words, forms and meanings were adopted in the English of ... trilingual individuals ... Some of these words, forms and meanings spread from specialist to more general discourse, and from the usage of particular social groups to the usage of the general population.

This process of diffusion from specialist to non-specialist sectors of the community is supported by Ingham, Sylvester \& Marcus (forthcoming), who identified occupational domains such as shipping and metalworking as areas where the penetration of French-origin lexis was of particularly significance. Ingham \& Marcus (2016) reviewed evidence for working knowledge of French in late thirteenth- and early fourteenth-century England in various professional domains. By that time there were few, if any, monolingual speakers of French residing in England (Trotter 2003b), so the substantial evidence of communication in that language for everyday practical purposes can be taken to indicate the presence of bilingual speakers in occupational and professional contexts. ${ }^{1}$ In the present article, the term 'bilingualism' will similarly be taken to refer to functional competence in the inherited variety of French (also known as Anglo-Norman), as well as a presumed native-speaker ability in English. The usage of bilingual speakers facilitated the spread to monolingual English speakers of some French loans, at least as regards technical terms used in those domains. This seems to have been particularly the case as regards innovative terminology, such as in shipping (Trotter 2003c; Kowaleski 2007), cloth and clothing (Sylvester \& Chambers 2010) and medical terminology (Hunt 1997, 2000; Green 2009).

However, borrowing lexis to fill lexical gaps will not account for more than a fraction of the loans from French known to have entered Middle English. French contributed lexis to English much more widely than in professional and occupational terminology. Baugh \& Cable (2002: 73) went so far as to claim a 'general ... adoption of French words in every province of life and thought'. This influence has contributed to the well-known phenomenon in more recent English lexis of 'layering' (see Molencki, this volume): words originating as loans, especially from Latin, Greek or French, constitute a layer used for formal purposes and registers, such as scientific English,

1 Whether one might prefer to characterise such speakers as advanced L2 speakers of French, rather than bilinguals, would greatly depend on issues such as age of first exposure and manner of acquisition: see Ingham $(2012,2015)$ for extensive discussion of these questions in relation to what is known of educational practices at the time. 
whereas native lexis is used for ordinary purposes, such as informal conversation. Such stratification in the lexicon is particularly evident where near-synonyms exist, e.g. thrill/excitement. Although numerous words are neutral, i.e. they do not belong to the layering system, those that do belong to it usually fall either side of a native/nonnative divide. In the Old English period, there is little evidence of layering in the lexicon, though a number of Latin-derived words were used, especially in religious discourse. McMahon (1994: 202) followed the textbook consensus in identifying 'the church, warfare, the arts and administration' as the areas with which French lexis was 'mainly connected', but observed that borrowed and native lexis 'came to occupy different registers'. Her register-oriented perspective on lexical contact effects seems a promising dimension along which French influence on English can be understood. The focus here will be on looking at how French-origin loanwords came to be diffused through the speech community at that time. In sociolinguistic terms, that requires us to ask: who were the agents of change? For Rothwell (1998: 156) words of ultimately French origin became part of the lexis of English as a result of the myriad daily contacts between Anglo-French and Middle English in the minds and under the pens of a whole literate class. This perspective seems to locate the process in the domain of written language, but at that period the amount of writing, especially in English, would have formed no more than a minute fraction of the overall use of English. Hence a mechanism which places the locus of contact in the spoken medium is far more plausible as an account of contact influence on the ordinary language of monolingual English speakers.

My contention will be that the primary agents of contact-induced lexical change were the clergy, who in the medieval period occupied two key roles, and did so in a spoken medium: they preached and they taught. ${ }^{2}$ These two activities where they exercised verbal hegemony gave them a far-reaching influence on the language of the wider community and thus on a broad sweep of its lexis, without limitation to particular real-world content domains. Their preaching, as reflected by the substantial amounts of Middle English homiletic text material (if not actual sermons) destined for layfolk surviving from the thirteenth and early fourteenth centuries, can be evaluated linguistically, revealing the inclusion of extensive French-origin loans. This study aims to gain an appreciation of the semantic range of Francophone loans found in one such text from around 1300, known as the Cursor Mundi, and builds on findings obtained from this text to seek an understanding of how members of the clergy acted as a channel of contact influence on the monolingual English population with whom they communicated.

2 They also acted as spiritual advisors and confessors, as in the case of the female English anchorite for whom Ancrene Wisse was written; this early thirteenth-century text is noteworthy for its heavily French-influenced lexis (Trotter 2003a). 
2 Preaching to layfolk as a context for French-origin lexical diffusion

The penetration of French-origin lexis into English in the thirteenth century was facilitated by a noteworthy combination of historical circumstances. It was at this time, in the high Middle Ages, that a trend towards increased frequency of preaching to layfolk can be discerned; in earlier times, it had been more or less the prerogative of bishops. In 1215, the Fourth Lateran Council promulgated the education of preachers among the secular clergy to instruct lay audiences in religious teaching, so that gradually parish priests took more of a role in preaching, being required in England from 1281 onwards to do so a minimum of four times a year. At the same time, certain monastic orders, especially the Dominicans and Franciscans, also involved themselves extensively in lay preaching, founding schools of theology that would train the regular clergy in this activity. I return below to the significance of these proselytising initiatives among both the secular and regular clergy.

The third contributory factor was the use of French in religious circles. At the highest levels, ecclesiastical correspondence from the thirteenth and fourteenth centuries shows considerable use of French (Ingham 2008), which is also known to have served as an everyday medium of communication among members of monastic communities (McKitterick, Morgan \& Short 2005). Although not a great deal is known of the background of the lower ranks of the clergy, most friars preaching and hearing confession seem to have been of English origin, according to Moorman (1947), to judge from village names used as surnames in ordination lists. They would not normally, therefore, have been of French origin. However, men in holy orders were required to be literate, i.e. to have attended school, and in thirteenthand early fourteenth-century England French was still used as a vehicle language for grammar school teaching. The Dominican Robert Holcot and the Benedictine Ranulph Higden, monks who were both writing around 1330 and describing contemporary circumstances in England, stated independently that in grammar schools Latin was construed through French. Evidently, pupils needed to have a good command of French to be able to carry out satisfactorily what would otherwise have been an impossible exercise. Further evidence of the use of French in English schools is found in Hunt's (1991) edition of curriculum texts used for teaching Latin; in the manuscripts containing these, the vast majority of the Latin terms glossed are given French counterparts, rather than being glossed into English. Future clerics would thus have possessed a functional command of French adequate for a scholarly context. Their ability in French, at least among those of them that taught through that medium, meant that they should be considered competent second-language speakers of the language. Even those of the clergy who were not fluent French users, because of the influence of those that were, would probably have used a variety of English permeated by Francophone loanwords.

During the thirteenth century, then, preaching in English to layfolk was increasing and it was being carried out by those with some competence in French. How frequently such sermons were delivered has been disputed, however (Owst 1926), and their 
content, as with most forms of oral language at that time, is not documented. Although some printed sermon collections from the later Middle Ages are extant in English, they are from well after the thirteenth century, and would mostly have been preached by religious figures of some standing, rather than simple parish priests. ${ }^{3}$ Because Owst's seminal research covered only the late medieval period (1350 onwards) and cites mainly fifteenth-century sources, little light is shed by his work on thirteenthcentury preaching, unless one assumes that conditions then were just as they were 200 years later. By that time, complaints about the ignorance of parish priests, and their reluctance to preach as they were required to, occurred so frequently as to make it impossible to doubt their accuracy (Owst 1926: 35-6). Still, the mid-fourteenthcentury Northern Homily Cycle refers to parishioners 'coming to church on Sunday to say their prayers and to learn God's teaching that they hear there'. This would suggest that some form of vernacular preaching to monolingual lay congregations was at least quite common, since they could hardly have been said to 'learn' from a sermon delivered in Latin. One may conclude that Sunday preaching by parish priests to layfolk was not rare, albeit not as routine as the church authority would have liked it to be.

Now parish priests were not the only ones addressing sermons to layfolk. By the thirteenth century Dominican and Franciscan friars commonly preached sermons, to the extent of creating rivalry with the secular clergy, who soon required them to obtain licences to preach. The records of the time are filled with complaints about the extent to which mendicant friars were preaching outside the church. They 'travelled from town to town in the Sunday and great feasts, to teach the people God's law' (Dives et Pauper, Prec. iii cap. xvi, cited in Owst 1926: 58). The friars usually gave sermons in open spaces and public squares, especially in urban areas, often attracting larger crowds than most churches could accommodate.

Preaching by friars should not be thought of as some casual unsystematic practice. According to O'Carroll (1980: 57) there was 'a Dominican educational system based at priories in Oxford, Cambridge and London which grew from modest beginnings in the early thirteenth century ... to a regionally organised nationwide network in the late thirteenth and early fourteenth centuries, helping to provide each diocese with its trained preachers'. Surname records of many of the ordinands trained by these institutions indicate that they came from the locality of the priory. They were thus presumably English native speakers, not friars from abroad, but since their education would have required knowledge of French, their bilingual status can safely be assumed. Franciscan houses likewise had schools of theology, with a close relationship with the largest institution in Paris to which two members of each school could be sent each year to study (Mulchahey \& Noone 2002). In this respect again, knowledge of French seems to have played an important part in the activities of friars.

Numerous members of the clergy studied and lived in bilingual communities which would have been quite well suited to acting as a matrix in which processes of contactinduced language change in the contemporary world are known to operate. Two

3 The Ross (1940) sermon collection includes some preached by curates (Owst 1926). 
important mechanisms for effecting change under contact conditions in a language are code-switching and code alternation (Thomason 2001). Code-switching is typically a spoken phenomenon among bilinguals; it is avoided where monolingual speakers are among the target audience. There is evidence for it in texts written in English in the medieval period (see especially Schendl \& Wright 2011b). Some indirect evidence for it in a spoken mode can also be detected in certain kinds of written document (Ingham 2009, 2011). Furthermore, one can assume that a medieval audience capable of understanding a spoken macaronic sermon was also capable of processing codeswitching in real-time conversation. Code alternation takes place when an individual uses one language in one routine setting, e.g. the home, and another language in another setting, e.g. the workplace. This would have been the case for regular clergy using French for clerical purposes, but English when dealing with monolingual English speakers, especially outside their home institutions. That said, the existence of bilingual (or trilingual) monastic communities did not necessarily have to act as a conduit for the diffusion of loan lexis into English. Timofeeva (2017) considers loans from Latin in the Old English period, concluding that 'strong ties within monastic communities would generally have prevented contact-induced lexical change from spreading outside the monasteries'.

By the thirteenth century, however, the situation had certainly changed, with the new emphasis on friars devoting much time to preaching to layfolk outside their communities, so the weak ties existing between them and the lay community would now have assumed much greater significance and facilitated lexical diffusion (see Timofeeva, this volume). With this background in mind, I shall next consider the nature of the French-origin lexis that homiletic authors of the period around 1300 were employing in their English.

\section{Data source and analysis}

Many, if not most, of the substantial texts that have survived from the Middle English period prior to the mid fourteenth century, such as Ormulum, Ancrene Wisse, the Northern Homily Cycle, the works of Richard Rolle, the Ayenbite of Inwit are attributable to authors belonging to the clergy. These are mostly works of religious instruction, rather than homiletic literature as such. A particularly rich potential source for investigating the semantic characteristics of French-origin loans that may have entered English thanks to the input of preaching by the clergy is the Cursor Mundi (Morris 1874-5), a very long Middle English poem of nearly 29,000 lines summarising Bible stories and ancient history. It survives in an unusually large number of manuscripts for the medieval period, and is therefore assumed to have been rather popular. Its sheer bulk, together with the extraordinary expense that must have been required to produce it in the medieval period, makes it hard to imagine it was diffused in written form to ordinary parishioners for private reading. It is very likely to have been intended as source material for one of more members of a clerical community to use in spoken form when preaching, so that monolingual English speakers among 
the faithful would have been exposed to French-origin lexis via oral input. ${ }^{4}$ The oldest version of the Cursor Mundi (henceforth $C M$ ) is thought to be represented by the Cotton manuscript, estimated as dating from around 1340, but the composition date of the work is conventionally taken as around 1300. Of the author nothing is known other than the fact that he was a cleric; the dialect of the oldest manuscript is Northern Middle English, so he is assumed to have been from the North. In the prologue, the author claims to write for unlearned English folk who do not know Latin or French. His reference to French shows that the numerous French-origin words he nevertheless used in his work, as will be seen, were no longer identified with a foreign language, but were felt to belong to an idiom understood by ordinary people, i.e. that they were by now unquestionably part of the English language.

The analysis procedure adopted was to sample this very long work, in the Cotton manuscript version edited by Morris, by taking 100-line excerpts at regular intervals, and then manually extracting from them items of French origin. ${ }^{5}$ Altogether, 1,200 lines were sampled, which averaged seven words each, thus giving a total sample size estimated at around 8,500 running words. Although this was only a fraction of the overall work, it was hoped that this periodic sampling procedure removed the risk of possible bias that might have been introduced had the data been restricted to a possibly unrepresentative continuous part of the text.

Lexemes were identified as French-origin on the basis of their etymology as given in the Middle English Dictionary. Lexical types, not tokens, were recorded. Derivational forms and their root forms, e.g. judgment and judge, were counted separately. This produced a total of 245 French-origin lexical items, which were analysed under a number of different headings on a post hoc basis. Five reflected the position favoured in the textbook literature, which tends to categorise French loans in terms of social structure and content domains: law, religion/morality, government/military, food and clothing, respectively. The remaining categories, for words where there was a lack of content domain specificity, were not distinguished semantically but were organised by parts of speech, though with a subdivision into abstract nouns and other nouns. The frequencies of items in the categories thus established are shown in table 1.

A little under 30 per cent of these lexical types fell into the social structure content domains previously noted; out of 76 such types, 69 (91 per cent) were nouns. It can be seen that loans within these content domains comprised a higher noun element than was the case outside them, where verbs and adjectives were quite well represented, even though nouns here were still in a majority, unsurprisingly in view

4 A reviewer suggests this would have allowed for the possibility of French-origin lexis to be clarified verbally using native terms, or even rephrased in the text actually delivered. This is indeed possible, though it should be noted that many of the French-origin terms are rhyming words, the replacement of which would have threatened the rhyming couplet verse form. Where such replacements occur in other manuscripts of $C M$, the whole passage is normally altered to make a new rhyming couplet with the alternative term.

5 An exception was made for the first sample, so as to avoid the author's prologue which stands apart from the biblical content of the rest of the work; a 100-line passage beginning of a section break at line 411 was chosen instead. 


\begin{tabular}{lrr}
$\begin{array}{l}\text { Table 1. French-origin lexical } \\
\text { type frequencies in Cursor } \\
\text { Mundi samples }\end{array}$ \\
\hline \hline Category & $\mathrm{N}$ & $\%$ \\
\hline Law & 8 & 3.2 \\
Religion/morality & 44 & 17.9 \\
Government/military & 20 & 8.2 \\
Food & 2 & 0.8 \\
Clothing & 2 & 0.8 \\
Abstract noun & 59 & 24.1 \\
Other noun & 49 & 20.0 \\
Verb & 37 & 15.2 \\
Adjective & 21 & 8.6 \\
Exclamation & 3 & 1.2 \\
TOTAL & 245 & 100.0 \\
\hline \hline
\end{tabular}

of what is known of borrowing more generally (see e.g. Matras 2009). The content domain-specific categories in table 1 included (in modern spellings for simplicity of recognition) the following terms representing what I have labelled 'government and military matters':

(1) palace, prince, archer, tower, siege, commander, throne, battle, host, barbican, bailey, quarrel ('archer's quiver').

This category was comprised mostly of nouns of concrete denotation whose definition appears to require reference to the exercise of power over society, or to warfare. It was deemed best to err on the side of inclusiveness, as for example with words such as palace, prince and tower, whose meanings do not inherently involve rule over society but which in the medieval period must surely have been associated with this conceptual domain. Representing religious and moral meanings are words such as:

(2) paradise, tabernacle, chaste, repent, annunciation, clerk, abstinence, lechery, prophecy, spirit, sacrifice.

Again, not all were as strictly religious in their meaning as e.g. tabernacle and annunciation, but many, such as chaste and repent, presuppose the existence of a moral domain which at that period would have been entirely under the aegis of religious teaching. A slight majority in this category were abstract nouns. Terms where a legal meaning seemed central were, for example:

(3) judge, felony, prison, pardon, case, heritage

Mantle and spice are examples of items belonging to the clothing and culinary domains, respectively.

With a total of 76 items in these content domain-defined categories, there is no doubt that the traditionally evoked social structure approach to classifying lexical loans from 
French is quite well represented in the lexis of the $C M$. The fact remains, however, that the great majority of its French-origin lexical types, accounting for around 70 per cent of the total, fell outside the content domains that were identified, even on the basis of taking a fairly generous interpretation of content domain-specific lexis, as mentioned above in connection with palace etc. The largest single group is represented by words denoting abstract concepts, such as:

(4) doute ('fear'), age, peace, peril, folly, counsel, reason, joy, state, strife, poverty, manner.

These made up nearly a quarter of the total. Other (non-abstract) nouns accounted for a further 20 per cent approximately, to which must be added the non-domain specific verb category (c. 15 per cent). The abstract nouns are particularly interesting, covering a wide range of denotata ranging from mental and emotional states (joy, intent, delight) to human interaction (council, vengeance, service, outrage, malison (i.e. 'curse'), bounty (i.e. 'goodness'), to nouns denoting very general states of affairs (peril, state, poverty, deliverance). The additions French made to the lexicon of abstract concepts are thus well illustrated here. Another very important contribution was in the verb lexicon, especially in terms of lexicalising concepts of interactive behaviour, of which numerous examples appear:

(5) confirm, prove, mate (i.e. 'check'), tempt, comfort, blame, honour, reney (i.e. 'deny'), advise, serve, visit.

Of the remaining categories, the meanings of the 21 adjectives were again of widespread applicability, rather than relating to restricted content domains, e.g.:

(6) bold, diverse, clear, precious, gentle, gracious, loyal, certain, false.

It is true that the connotations of these items would have been with French culture in some cases (e.g. gentle, gracious, loyal), but their denotations cannot usually be handled in terms of social structure categories, that is, the properties that, as adjectives, they semantically attribute to individuals do not seem reducible to particular content domains. Certainly, many of them would become rather familiar items in the fourteenth century in the courtly romances translated from French. But to find them in homiletic material composed around 1300 suggests that they were by this time already known to ordinary English monolingual audiences, before the rise of English-language romances. My contention, then, is that well before the end of the thirteenth century such vocabulary was used in their preaching quite generally by clerical preachers, much as it was by the Cursor Mundi author, and that it was their input, not that of the courtly literature of the following century, that chiefly spread Francophone lexis among monolingual English speakers.

The French-derived lexis of the $C M$ is not in the main to be attributed to the predominance of Norman-origin speakers in high-status activities and domains of society. Rather, to judge from the examples quoted in (3)-(5) above, the lexis employed here appears to evoke concepts that relate to the nonmaterial world, or in terms of 
Roget's well-known thesaurus categories: 'communication of ideas', 'volition' and 'the affections' (understood as human sensibility in some broad sense). In a spiritual work such as the $C M$, this dominance of nonmaterial lexis is hardly surprising, of course. What seems significant is that by the presumed composition date of the $C M$, around the beginning of the fourteenth century, many concepts in these semantic spaces had seen replacement of native by French terms in the (at least) receptive vocabulary of the less well-educated part of the population. These concepts represent wider areas of mental and emotional life, not just particularities of Norman-dominated social spheres. Their introduction into English did not, therefore, reflect material-world hegemonic dominance, the leitmotif of so much earlier discussion of French contact influence on English, so much as the spiritual and intellectual influence exercised by the clergy.

Importantly, the content lexis of the homiletic material used for preaching, as indicated by the $C M$, ranged widely over aspects of ordinary life to which a lay congregation could easily relate. It featured episodes from the Old Testament relating narratives of humanly understandable situations where morality rather than social status was at issue. It did not usually address the chivalrous and amorous topoi explored in popular forms of medieval literature, especially romances, which offered descriptions of high-status characters, their surroundings and their activities. Nevertheless, because it was used in a context which enjoyed social prestige, it can be seen as having contributed to the creation of a 'high' register in which to evoke concepts involved in biblical narratives but also familiar from a layperson's everyday life, such as joy, peril, blame, tempt etc. Many such items, e.g. blame and tempt, would in fact pass into the general vocabulary of English, so membership of this high register would have been only temporary in such cases. But a tendency towards the layering of English lexis present in the modern language can already be seen in some of the items represented in the $C M$.

If by the end of the thirteenth century a monolingual English audience could be assumed to know the 245 French-origin lexemes used in the passages sampled, the question arises as to how its author was able to make such an assumption. The proposal advanced here is that he and others in his position were able to rely on extensive prior knowledge of French-origin lexis in English precisely because they themselves were chiefly responsible for introducing it to the general public. For this to have been the case, a number of factors needed to have been in place. First, to have acted as a source of contact influence on a wide range of English speakers, the clergy required knowledge of both French and English. As we shall see directly, this assumption is a valid one. Secondly, their influence would need to have operated considerably before the point when the $C M$ was written, so that French-origin lexis would have had time to diffuse and become recognisably familiar to the average English monolingual. Some indication of the time-frame involved is given by the fact that the long religious poem Ormulum, thought to have been composed about a century earlier than the $C M$, contains very little French-origin lexis (Skaffari 2009). The author of this text is known to have had great concern 
for the reception of his work, as evidenced by the care he took to indicate how it should be read aloud, so he is very likely to have been similarly concerned to avoid unfamiliar vocabulary items. Contextual factors such as being of Scandinavian origin may certainly have played a part, but taken together these two works of religious instruction testify to a strikingly higher level of awareness of Frenchderived lexis among congregations at the end of the thirteenth century than at the beginning.

The timing of French influence on English lexis, which grew massively in the thirteenth century, can best be understood in terms of this pastoral context. This, as mentioned above, was the period following the Fourth Lateran Council when the church increased its emphasis on caring for the spiritual welfare of the laity by preaching. Both secular and regular clergy participated in this enhanced activity. So the rise in French words seen as having entered English by the end of the century followed the greater intensiveness of opportunities during the thirteenth century for the clergy to communicate with layfolk. Priests needed to be literate in order to carry out the demands of their profession, and as mentioned earlier, until the fourteenth century grammar school education took place via French, so the clergy must have been conversant with French as a second language, if not fluent in it. The thirteenth century was also a time that saw a large increase in grammar schools (Leach 1915; Orme 1973), and thus in the size of the population exposed to French through the school system.

How confident can one be that an adequate knowledge of French existed in clerical communities for their members to act as agents of contact-induced change? At this time the use of French in England showed no signs of the sharp decline that was to set in during the course of the following century (Ingham 2011, 2012; Short 2007). In particular, large numbers of works in Anglo-French were being composed and copied in religious houses. Now, it must be kept in mind that French was by this time used in England almost entirely by bilingual English native speakers. Certainly, the lower levels of the clergy would not usually have been of French origin: for one thing, the requirement for parish priests to give weekly sermons in English, restated early in the thirteenth century after a period of neglect, would have militated against the appointment of continental French speakers, who would normally have lacked fluency in English. The clergy, to a considerable degree, must therefore have constituted a bilingual population, since monolingual speakers of French in England are generally taken to have become rare by this time. In the next section, a perspective will be taken on how bilingualism allows contact effects to take place via the coexistence of two linguistic systems, and how this could have facilitated lexical loans in the medieval context studied here.

\section{Bilingual activation in speech production}

In the foregoing section I have shown that French-origin lexis is fairly common in the $C M$ and covers a wide range of semantic space not restricted to the social structure 
content domains favoured in earlier discussions of Francophone lexical influence on English. It remains to consider how in practice the fact of bilingualism among clerical communities can be taken to have favoured the introduction of French-origin lexemes into English, and in particular what contact mechanism was at work. As stated earlier, I do not see this as a matter of recipient language agency, as in a conventional borrowing scenario, but rather as part of the mutual influence of one language on another within a bilingual speaker's competence. Current psycholinguistic research has investigated how both of a bilingual person's languages can be activated in speech processing. There is by now a very extensive body of research on this topic, obtained from a wide range of bilingual contexts, which generally tend to establish the reality of some kind of dual activation, although important nuances have been expressed. Space restrictions prevent us from fully doing justice here to the richness of the findings obtained, so mention will be made of a small number of studies representing key outcomes and also contentious issues. Spivey \& Marian (1999) found that accessing a word in one of a bilingual's languages which is phonologically similar to a word in the other language may activate the latter item. In later work, however, they observed that this may be facilitated by holding the test procedure in a background which favours the use of both languages (e.g. by testing for Russian in an English-speaking country, as in their original procedure), and some caution is urged by Grosjean \& Li (2013) in interpreting the results of such research findings. Recent studies have overcome such initial methodological problems in identifying the potential role of the other language in bilingual speech. Colomé \& Miozzo (2010), who tested in entirely monolingual settings, found activation of other-language lexemes in comprehension. Hatzidaki, Branigan \& Pickering (2011) found that in production the grammatical systems of both languages were activated. What seems a currently viable position in the bilingual activation research field has been stated by Shook \& Marian (2013: 304) as: 'During speech comprehension, bilinguals co-activate both of their languages, resulting in cross-linguistic interaction at various levels of processing.'

Inevitably, further refinements and deeper understanding can be expected to modify some of the specifics involved in the bilingual activation research area, but for present purposes it seems valid to infer that contact effects on lexis can be implemented through the simultaneous activation of lexemes in a bilingual's two languages. Taking the lexicon to be semantically an associative network, it can be posited that the bilingual lexicon (de Bot \& Schreuder 1993; Kroll \& De Groot 2005) associates lexemes of the two languages with a concept; activation of both lexemes occurs when the concept is accessed. When producing speech in one particular language a bilingual will normally select only the lexeme from that language. Nevertheless, an associative link can be taken as being present between the selected and unselected forms, which I propose could facilitate the use of other-language items in speech production, in effect constituting one-word code-switching or nonce borrowing (Poplack 2012). Within bilingual communities, such language-mixing practices can favour the adoption into one language of other-language items. 
Making what seems to be a reasonable assumption that the psycholinguistics of human language processing have not changed materially over the centuries, ${ }^{6}$ even though of course societal and cultural settings will have, we can extrapolate these contemporary findings back to the use of language by bilinguals of the period under study. The expectation would then be that both languages would to some extent have been activated in the linguistic praxis of members of bilingual speech communities, such as clerical ones. This, I propose, influenced the lexical selection employed in works they composed, such as the $C M$. These texts are known to have been used as a source of memorised material for sermons - the rhyming verse form would have been useful for this purpose. Such texts as the $C M$ should therefore be seen as attesting to the circumstances of their composition, not of their delivery. Even if the church or other place used for preaching were resolutely monolingual in character, this in itself would scarcely have influenced the circumstances of composition. The composition of the $C M$ and other such materials would have taken place within the walls of bilingual clerical communities; recent psycholinguistic research suggests this would have favoured the activation of both languages. When composing in English, the clerics' French would also have been activated. So when a semantic concept the author wished to express was accessed, the corresponding lexical items of both languages became available, a scenario which could result in the selection of the French item as a one-word code switch, or the reinforcement of the French-origin equivalent already in English.

Note, however, that the process described above does not explain how a Frenchorigin item came to enter the passive competence of a monolingual English audience. To understand how this came about, it should be borne in mind that for the most part the writer of the $C M$ must have assumed his audience already knew French origin items, at least for recognition purposes. This means that an earlier process of gradual diffusion of such terms into their passive competence has to be posited. This in my view should be seen as originating in the practice of spoken code-switching, of which members of bilingual clerical communities would in many cases have been capable. No doubt some explanation and negotiation of meaning in the course of those contacts between clergy and faithful would have been necessary, as indeed must be the case when new lexemes are picked up by monolinguals more generally. In short, the recognition ability of sermon audiences as regards French-origin lexemes should be seen as the endpoint of a process of gradual familiarisation, on which the author of the $C M$ felt able to rely in using them. The most likely form this process took would have been the repeated use by the clergy of the relevant lexical items in their pastoral interaction with their congregations, thus enabling writers of texts such as the $C M$ to build on that basis.

6 As suggested by a reviewer, Labov's (1972) Uniformitarian Principle, which holds that the causes of change in the present are largely the same as those operating in the past, is relevant here. If we assume that language processing today is unlikely to have changed significantly from the human ability to process language in earlier times, changes to medieval states of language would have taken place within the same set of psycholinguistic affordances and constraints as those of today. 


\section{Conclusion}

The findings from the Cursor Mundi samples show that about 70 per cent of the French-origin loans encountered should be seen as belonging to the general vocabulary of Middle English, not as members of socially specific lexical domains such as religious/moral or aristocratic/military matters. They were not terms that would have been used by the social and religious elite to designate specialised aspects of their roles in life. Much of the material borrowed seems to have been far too general in its application to apply only to upper-social-class content domains (see also Durkin, this volume). Such loan lexis did not typically come into English via knights and nobles conversing with commoners about noble pursuits and fashionable accoutrements. Whereas lexis such as siege, barbican, penance and procession got into English because those who now controlled the military and spiritual life of the country imposed the French terms words for them, in the case of words such as (to) plant, branch, strife and beast no such specialised contexts would have provided the occasion for borrowing lexis for such denotata already furnished with native words. For lexemes such as those analysed here to have been at least in the recognition vocabulary of presumed monolingual English speakers around 200 years after the Conquest, these borrowed items must have been diffused beyond the usage of a bilingual speech community well before that point. The clergy brought monolingual speakers into contact with Frenchorigin lexis, in so doing creating a French-influenced high register of English that was underway before the end of the medieval period.

A crucial issue in this contact influence process explored in this article is the setting in which originally French-only items found themselves in the lexicon of Middle English. I have proposed here that the milieu in which English-speaking clerics educated in French lived and worked in the high medieval period provided the requisite contact conditions via individual bilingualism. Based on research into the psycholinguistics of contemporary bilingualism, my contention is that the at least partial activation of languages in the interaction of bilingual members of clerical communities would have afforded constant opportunities for French lexemes to be activated during discourse in English. This gave rise to code-switching, and eventually the borrowing of the French items into English. In this connection, the view of Thomason (2001) that code-switching and borrowing are not wholly distinct entities, but different ends of a continuum, seems highly apposite. They would, in the perspective adopted here, be psycholinguistically part of a single dynamic process by which words in speakers' actual language praxis are adopted from one language into another. This would, then, seem a plausible route by which much French-origin lexis came to occupy lexical spaces in English.

Although other channels certainly existed in the medieval period for Francophone lexis to be borrowed, the role of the clergy, as the 'media' of the day, in influencing the lexical character of English can hardly be overstated. They formed the ordinary layperson's point of contact with the new trends in language that society of the time, thanks to the French heritage of its ruling elite, was following. Taking up that 
inheritance, and with the authority of the sacred word, clerics enjoyed a uniquely favoured position from which to inform the linguistic direction of travel of the wider community of English speakers. Texts such as the $C M$ may be seen as attesting to how successful they were.

Author's address:

Department of English, Linguistics and Cultural Studies

University of Westminster

32-38 Wells St

London WIT $3 U W$

$U K$

r.ingham@westminster.ac.uk

\section{References}

Baugh, Albert \& Thomas Cable. 2002. A history of the English language, 5th edn. London: Routledge.

de Bot, Kees \& Robert Schreuder. 1993. Word production and the bilingual lexicon. In

Robert Schreuder \& Bert Weltens (eds.), The bilingual lexicon, 191-214. Amsterdam: John Benjamins.

Berndt, Rolf. 1972. The period of the final decline of French in medieval England (14th and early 15th centuries). Zeitschrift für Anglistik und Amerikanistik 20, 341-69.

Colomé, Angels \& Michele Miozzo. 2010. Which words are activated during bilingual word production? Journal of Experimental Psychology: Memory, and Cognition, 36(1), 96-109.

Dekeyser, Xavier. 1986. Romance loans in Middle English: A re-assessment. In Dieter Kastovsky \& Aleksander Szwedek (eds.), Linguistics across historical and geographical boundaries, 253-66. Berlin: Mouton de Gruyter.

Durkin, Philip. 2014. Borrowed words. Oxford: Oxford University Press.

Hatzidaki, Anna, Holly Branigan \& Martin Pickering. 2011. Co-activation of syntax in bilingual language production. Cognitive Psychology 62(2), 123-50.

Green, Monica. 2009. Salerno on the Thames: The genesis of Anglo-Norman medical literature. In Wogan-Browne et al. (eds.), 220-31.

Grosjean, François \& Ping Li. 2013. The psycholinguistics of bilingualism. Chichester: Wiley-Blackwell.

Hunt, Tony. 1991. Teaching and learning Latin in thirteenth-century England. Rochester, NY: Boydell.

Hunt, Tony. 1997. Anglo-Norman medicine. Cambridge: D. S. Brewer.

Hunt, Tony. 2000. Code-switching in medical texts. In David Trotter (ed.), Multilingualism in later medieval Britain, 131-47. Cambridge: D. S. Brewer.

Ingham, Richard. 2008. The Anglo-Norman Correspondence Corpus. RDUES, Birmingham

City University. http://wse1.webcorp.org.uk/anglo-norman/

Ingham, Richard. 2009. Mixing languages on the manor. Medium Avvum 78, 80-97.

Ingham, Richard. 2011. Code-switching in the later medieval English lay subsidy rolls. In Schendl \& Wright (eds.), 95-114.

Ingham, Richard. 2012. The transmission of Anglo-Norman: Language history and language acquisition. Amsterdam: John Benjamins. 
Ingham, Richard. 2015. The maintenance of French in later medieval England. Neuphilologische Mitteilungen 115(4), 623-45.

Ingham, Richard \& Imogen Marcus. 2016. Vernacular bilingualism in professional spaces, 1200 to 1400. In Albrecht Classen (ed.), Multilingualism in the Middle Ages and early modern age: Communication and miscommunication in the premodern world, 145-64. Berlin: De Gruyter Mouton.

Ingham, Richard, Louise Sylvester \& Imogen Marcus. Forthcoming. Penetration of Frenchorigin lexis in Middle English occupational domains. In Michela Cennamo \& Claudia Fabrizio (eds.), Historical Linguistics 2015: Selected papers from the 22nd International Conference on Historical Linguistics, Naples, July 2015. Amsterdam: John Benjamins.

Kastovsky, Dieter. 2006. Vocabulary. In David Denison \& Richard Hogg (eds.), A history of the English language, 199-270. Cambridge: Cambridge University Press.

Kowaleski, Maryanne. 2007. 'Alien' encounters in the maritime world of medieval England. Medieval Encounters 13, 96-121.

Kroll, Judith \& Annette De Groot (eds.). 2005. Handbook of bilingualism: Psycholinguistic approaches. New York: Oxford University Press

Labov, W. 1972. Some principles of linguistic methodology. Language and Society 1(1), 97-120.

Leach, Arthur. 1915. Schools of medieval England. London: Methuen.

Matras, Yaron. 2009. Language contact. Cambridge: Cambridge University Press.

McKitterick, David, Nigel Morgan, Ian Short \& Teresa Webber (eds.). 2005. The Trinity Apocalypse. Toronto: University of Toronto Press.

McMahon, April. 1994. Understanding language change. Cambridge: Cambridge University Press.

Moorman, John. 1947. The foreign element among the English Franciscans. English Historical Review 62(244), 289-303.

Morris, Richard (ed.). 1874-1875. Cursor Mundi: A Northumbrian poem of the XIVth century in four versions (Early English Text Society OS 57, 59). London: Keegan Paul, Trench, Trübner \& Co.

Mulchahey, Michèle \& Timothy Noone. 2002. Religious orders. In Jorge Garcia \& Timothy Noone (eds.), The Blackwell companion to philosophy in the Middle Ages, 45-54. Oxford: Blackwell.

O'Carroll, Maura. 1980. The educational organisation of the Dominicans in England. Archivum Fratrum Praedicatorum 50, 23-62.

Orme, Nicholas. 1973. English schools in the Middle Ages. London: Routledge.

Owst, G. R. 1926. Preaching in medieval England: An introduction to sermon manuscripts of the period c.1350-1450. Cambridge: Cambridge University Press.

Poplack, Shana. 2012. What does the nonce borrowing hypothesis hypothesize? Bilingualism: Language and Cognition 15, 644-8.

Ross, Woodburn. 1940. Middle English sermons (Early English Text Society 209). London: Oxford University Press.

Rothwell, William. 1998. Anglo-Norman at the (green)grocer's. French Studies 52(1), $1-16$.

Schendl, Herbert \& Laura Wright (eds.). 2011. Code-switching in early English. Berlin: De Gruyter Mouton.

Shook, Anthony \& Viorica Marian. 2013. The bilingual language interaction network for comprehension of speech. Bilingualism: Language and Cognition 16, 304-24.

Short, Ian. 2007. Manual of Anglo-Norman (Anglo-Norman Text Society Occasional Publications Series no. 7). Oxford: Anglo-Norman Text Society. 
Skaffari, Janne. 2009. Early Middle English loanwords: Norse and French influences (Anglicana Turkuensia 26). Turku: University of Turku, Finland.

Spivey, Michael \& Viorica Marian. 1999. Cross talk between native and second languages:

Partial activation of an irrelevant lexicon. Psychological Science 10(3), 281-84.

Sylvester, Louise \& Mark Chambers. 2010. From apareil to warderobe: Some observations on Anglo-French in the Middle English lexis of cloth and clothing. In Richard Ingham (ed.), The Anglo-Norman language and its contexts, 63-73. Woodbridge: Boydell \& Brewer.

Thomason, Sarah. 2001. Language contact: An introduction. Edinburgh: Edinburgh University Press.

Thomason, Sarah \& Terence Kaufman. 1988. Language contact, creolisation, and genetic linguistics. Berkeley: University of California Press.

Timofeeva, Olga. 2017. Lexical loans and their diffusion in Old English: Of 'gospels', 'martyrs', and 'teachers'. Studia Neophilologica 89(2), 215-37.

Trotter, David. 2003a. The Anglo-French lexis of the Ancrene Wisse: A re-evaluation. In Yoko Wada (ed.), A companion to Ancrene Wisse, 83-101. Cambridge: D. S. Brewer.

Trotter, David. 2003b. Not as eccentric as it looks: Anglo-French and French French. Forum for Modern Language Studies 39, 427-38.

Trotter, David. 2003c. Oceano vox: You never know where a ship comes from: On multilingualism and language-mixing in medieval Britain. In Kurt Braunmüller \& Gisela Ferraresi (eds.), Aspects of multilingualism in European language history, 15-33. Amsterdam: John Benjamins.

Wogan-Browne, Jocelyn, Carolyn Collette, Maryanne Kowaleski, Linne Mooney, Ad Putter \& David Trotter (eds.). 2009. Language and culture in medieval Britain: The French of England, c.1100 - c.1500. Woodbridge: Boydell \& Brewer. 